Article

\title{
Comfort as a Service: A New Paradigm for Residential Environmental Quality Control
}

\author{
Juan Gómez-Romero®, Miguel Molina-Solana *®i, María Ros, M. Dolores Ruiz \\ and M. J. Martin-Bautista \\ Department of Computer Science and Artificial Intelligence, Universidad de Granada, 18071 Granada, Spain; \\ jgomez@decsai.ugr.es (J.G.-R.); marosiz@ugr.es (M.R.); \\ mdruiz@decsai.ugr.es (M.D.R.); mbautis@decsai.ugr.es (M.J.M.-B.) \\ * Correspondence: miguelmolina@ugr.es
}

Received: 11 July 2018 ; Accepted: 24 August 2018 ; Published: 28 August 2018

\begin{abstract}
This paper introduces the concept of Comfort as a Service (CaaS), a new energy supply paradigm for providing comfort to residential customers. CaaS takes into account the available passive and active elements, the external factors that affect energy consumption and associated costs, and occupants' behaviors to generate optimal control strategies for the domestic equipment automatically. As a consequence, it releases building occupants from operating the equipment, which gives rise to a disruption of the traditional model of paying per consumed energy in favor of a model of paying per provided comfort. In the paper, we envision a realization of CaaS based on several technologies such as ambient intelligence, big data, cloud computing and predictive computing. We discuss the opportunities and the barriers of CaaS-centered business and exemplify the potential of CaaS deployments by quantifying the expected energy savings achieved after limiting occupants' control over the air conditioning system in a test scenario.
\end{abstract}

Keywords: comfort as a service; energy management; building control; big data; ambient intelligence

\section{Introduction}

The current building regulatory framework, through international and national standards and laws, dictates a number of requirements and recommendations aimed at the efficient use of energy and the reduction of consumption. However, not every energy saving measure is acceptable because they must be implemented while ensuring acceptable comfort for occupants. Therefore, regulations usually push (and in many cases, even oblige) new buildings to be safe and sustainable, but also comfortable for prospective users.

Indoor Environmental Quality (IEQ) denotes, precisely, how well a building meets the comfort requirements of the occupants in terms of health, well-being and productivity [1]. IEQ comprises many different aspects, such as thermal comfort quality, air quality, odor quality, light quality, sound quality and vibration quality, to name some of them. Operation and maintenance activities in the building are also factors that have an effect on IEQ [2]. All of them together provide welfare to the human body; and even if only one fails, the indoor quality is strongly affected. Nevertheless, it is widely accepted that thermal comfort is by far the most important aspect that concerns occupants [3], the most energy-demanding [4] and the most difficult to optimize due to thermal inertia and disturbances [5].

Although the quality of the indoor environment should be considered in all stages of the building's life-cycle (i.e., design, construction and operation), it is during the operational phase when the comfort control actions have the greatest impact on users. Therefore, it is necessary to define and implement suitable control policies in the daily building operation to minimize energy consumption while guaranteeing a minimum user comfort level. The imprecise concept of minimum comfort has been 
defined in different standards, like EN-15251 in the European Union [6] and ASHRAE 55-2017 [7] in the United States, by establishing a range of acceptable values for different aspects of the indoor comfort according to energy efficiency criteria. Not surprisingly, most of these proposals only consider public buildings, even though residential buildings account for a great deal of the energy spent in trying to provide comfortable conditions in an inefficient way.

In both residential and public scenarios, the most extended comfort control approach nowadays is direct human control, in which a more or less specialized operator is in charge of constantly monitoring the building conditions and adjusting the operation of the equipment according to the available information and her/his previous experience. This kind of control, while easy and direct, presents a set of undesirable features that, however, go largely unnoticed for most users. In particular, we identify the following drawbacks:

Reactive: Users act on the equipment principally when they realize that the comfort has been completely lost, but not before diminishing the decline.

Inaccurate: Users tend to overcompensate wrong settings when manual control of the equipment is available.

Irregular: Actions to control comfort are not appropriately distributed in time, which leads to unbalanced energy demands and difficulties in predicting costs.

Local: Comfort control is not part of a more general operational plan that could increase energy savings by applying long-term optimizations.

Our proposal advocates for a paradigm shift in the way that consumers operate their HVAC equipment (Heat, Ventilation and Air-Conditioning). We suggest that users should hand over the control of their systems to an energy savings company that would automatically and efficiently operate them according to agreed comfort levels. We call this new paradigm Comfort as a Service (CaaS), in line with the recent business models that propose offering diverse services without requiring a deep understanding of the supporting technologies. In CaaS, the user is no longer in direct control of the indoor temperature, ambient lighting and other conditions. Users are served comfort, and it is the utility, the facility service or the building management system that is in charge of tuning the relevant parameters to achieve comfort at a minimum cost. For the aforementioned reasons, in this work, we focus on thermal comfort and HVAC operation, but the approach is extensible to other IEQ aspects.

CaaS is heavily based on the rationale behind cloud computing, which transparently provides computational resources at any time anywhere, and the potential of big data, ambient intelligence and predictive computing technologies to understand what is happening in a complex environment and to react conveniently. The CaaS concept was key in the approach investigated by the Energy IN TIME project (Energy IN TIME: Simulation-based control for energy efficiency building operation and maintenance was funded by the 7th Framework Program of the European Commission in 2013-2017; http:/ / www.energyintime.eu), within which this research work was developed.

This article describes the current state of affairs in this area, how it may evolve and the challenges that lie ahead. After this introductory section, we elaborate on the concept of comfort as a service (Section 2), and explain in detail the enabling technological framework (Section 3). We also develop a SWOT (Strengths, Weaknesses, Opportunities and Threats) analysis of the social and economic implications of CaaS (Section 4). Finally, we present an experiment carried out in the Energy IN TIME project showing the potential benefits of CaaS in a simulated environment representing a real hotel building (Section 5).

\section{Comfort as a Service Concept}

\subsection{Motivation}

The growth of the service economy in the last few decades has popularized the term 'service' to describe almost any kind of resource supply; e.g., energy, water, cable TV, broadband Internet access 
and mobile communications. Service providers must cover different roles of the process, which can be played by the same or different organizations.

Broadly speaking, there are three main economic models for service provision, with different Service-Level Agreements (SLAs) associated:

Pay-per-use: This is the most straightforward model. In pay-per-use, users are charged for the precise amount of resources consumed during a period according to a fixed unit price or, more rarely, a time-fluctuating tariff. The payments are therefore variable between periods and fairly unpredictable.

Subscription with limits: Once a service is mature enough, a subscription is the natural evolution of the pay-per-use model. In this model, users pay a fixed and regular amount to enjoy the service during several consecutive time periods. The service company benefits from this schema, because it favors a predictable regular revenue and the estimation of the service demand, as well as the anticipation of future needs and profits. To prevent abuse by very demanding users, companies often block the access to the service when a maximum consumption threshold is exceeded.

Subscription without limits: Besides limiting the access to the service, there are other options to make viable the subscription model and avoid overuse. Some strategies in this direction are the application of a substantial increase of the monthly fee, the increment of the price of the resources consumed over the threshold or the reduction the quality and the availability of the service. A different approach is pairing the service with another one in such a manner that, when the usage of the first one increases, the revenue from the second one increases, as well.

These three models can be eventually commercialized on their own or as a combination of them. In fact, most providers tend to offer a regular subscription model that falls back to pay-per-use once the limits have been reached. In all cases, it is frequent to have additional fees that may or may not depend on the amount of resources consumed, such as taxes, renting of equipment and infrastructure maintenance.

In the context of energy provision services, the most common paradigm is that customers pay for the consumed energy: the pay-per-use model. A great deal of the consumption is due to pieces of equipment responsible for maintaining comfort, which are directly controlled by users themselves. This model can evolve to a subscription with limits model, in which the customers pay a fixed amount for obtaining (ideally) enough energy to satisfy their comfort needs. Again, the users are in charge of operating the equipment to achieve comfort.

Current technological advances promote further developments in the economic models for the provision of energy. The comfort as a service paradigm defines a schema in which: (i) the company offers a subscription (without limits) to always provide a comfortable indoor environment; and (ii) the user hands over the control of the equipment. In CaaS, customers do not pay any more for the energy spent to achieve comfortable indoor conditions. Instead, they pay a fixed amount for being comfortable, and it is the service provider that delivers the comfort through a combination of infrastructures and processes. It is in the best interest of the company to reduce the cost of the service, which can be achieved by (partial or total) automation, implementation of optimized control strategies and obtaining better estimations of demand and supply. Of course, users should always be allowed to take back control, probably shifting to the first or the second payment model.

The following example illustrates the CaaS concept. Without lack of generality, we focus this description on thermal comfort and ambient lighting. In this scenario, the user and the service provider have agreed that, on exchange of a monthly amount, the provider will monitor and control the user's energy appliances, guaranteeing a home temperature in the interval $[19,22]{ }^{\circ} \mathrm{C}$ and a moderately illuminated ambiance during the day. Let us assume that it is a winter day:

- If it is a very cold day, heating will be needed throughout the whole day. This means a higher use of the HVAC unit to keep the house in the acceptable $\left[19,22{ }^{\circ} \mathrm{C}\right.$ range, compared to the usual 
operation. The service provider will optimize the consumption as much as possible, assuming any extra cost. The user does not need to worry about the operation of the equipment or the increased consumption. Likewise, if it is also a cloudy day, the provider will need more energy to maintain the lighting requirements.

- If it is a warmer and sunny day, heating might not be needed at all to maintain the service level. Therefore, the service provider will not need to activate the HVAC and lighting equipment and will save costs, thus making a profit. Like in the other scenario, the user will not need to worry about operation of the equipment.

\subsection{Operation and Control}

The characteristic feature of the CaaS paradigm is therefore that users cede the control of their devices to a third party, which operates them to maintain the comfort levels inside an agreed range with a minimum cost. The complete comfort supply chain in CaaS may involve more than one company, because the creation of the infrastructure in the customer residence, the maintenance of the equipment and the energy production, transport and distribution tasks may be performed by different energy service companies. In the remainder of the paper, we will focus on the activities related to the operation of the users' HVAC equipment.

Note that the notion of comfort has been extensively considered in the IEQ literature, particularly in relation to thermal comfort [8]. A classical comfort measure is the standard Predicted Mean Vote (PMV), which aggregates multiple environmental factors to produce a single comfort index [9]. This measure has been often criticized for the difference of subjective comfort experienced by different kinds of users; e.g., male and female [10]. Hence, adaptive versions of PMV, capable of learning user-adapted comfort values, have been developed [11,12]. Therefore, we can assume that comfort is computed with a virtual sensor that aggregates several measurable factors and that may involve manual or automatic fine-tuning to meet user-specific preferences and needs.

HVAC optimization has been addressed in the literature by applying different control approaches. We can distinguish two main types of HVAC control solutions: homeostatic controllers and Model Predictive Controllers (MPC). The PID (Proportional-Integral-Derivative) controller is the most common kind of homeostatic direct controller. PIDs calculate the error between the current and the desired outputs and apply a correction to minimize this value based on the derivative of this difference over time [13]. PIDs are typically fast, but they do not account for optimizations over larger periods of time, which can be crucial when inertial (e.g., HVAC) or multiple-component (e.g., smart grids with energy production and storage) systems are involved. Fuzzy controllers, implementing a control logic expressed with imprecise terms and rules, are an alternative to PIDs [14]. MPCs, in turn, use a simulation model of the building to capture its dynamic characteristics and predict its response to alternative control scenarios [15]. MPCs better account for system inertial effects and improve long-term operation; in contrast, they are more expensive to create (they require an accurate simulation model to work well) and execute (running multiple simulations takes considerable time). A combination of MPCs for longer term optimization and PIDs/fuzzy controllers for shorter term control adjustment seems the most appropriate approach to implement control in the CaaS paradigm.

Optimization requires the incorporation of different data sources identifying the building current and future state. Current and forecast weather data are among the most relevant data sources because they influence the energy required to meet the comfort levels [16]. Additionally, building occupant activities have a significant impact on the environmental quality [17]. Comfort levels when users are performing physical activities at home are clearly different from those expected when watching television. In addition to these inputs, CaaS also needs to collect information about other impacting factors, such as passive elements such as building materials, equipment capabilities and potential energy losses, as well as energy prices. The technologies and methods to exploit all this information to achieve efficient comfort control are later described in Section 3. 


\subsection{User Behavior and Energy Consumption Awareness}

Several studies $[2,18,19]$ have confirmed that occupants' presence and behavior in buildings have a large impact on energy consumption. In order to achieve reductions in the building energy needs, two options are available: the first one is making users aware of their consumptions, as this tends to reduce their energy demand; and the second one is reducing the degree of control that occupants have on the building equipment. Therefore, increasing awareness of energy habits to avoid energy waste, on the one hand, and characterizing users' behavior to meet their needs, on the other, are central to the CaaS concept.

In the literature, we can find several contributions aimed at the first objective. For instance, Abrahamse et al. [20] used a web-based tool to show users a combination of customized information, goals and feedback. After five months, they reported that households exposed to the tool saved up to $5.1 \%$ of energy and adopted several energy-saving routines. Before, these authors had reviewed alternative methods to evaluate the effectiveness of interventions to promote household energy conservation and to make suggestions on how to improve the understanding of effective intervention planning [21].

Regarding the second objective, with the advent of smart energy meters, companies have more data available than ever and can take advantage of that information to extract valuable knowledge beyond billing purposes [22]. One relevant piece of knowledge is users' behavioral patterns and activities, since companies can use this information to estimate energy loads and to account for expected consumption patterns and peaks. In this regard, the authors in [23] quantified customers' influence in energy consumption by extracting patterns of appliances' use automatically; in [24], data mining techniques to identify inefficient energy usage were developed; and in [25], it was found that high electrical consumption in Kuwait was due to always-on lighting and overcompensation of HVAC setpoints. Some authors have argued that, besides modeling user activities, it is also relevant to consider the impact of the occupants' passive behavior (e.g., generated heat and $\mathrm{CO}_{2}$ ) on the indoor conditions. For example, in [26], data mining was applied to identify and learn this passive behavior in an office building.

\section{Technological Framework}

In this section, we briefly describe the main enabling technologies for CaaS and how they all fit together to successfully implement it.

\subsection{Enabling Technologies}

Ambient Intelligence: As explained above, in the CaaS paradigm, the provider automatically controls the comfort equipment, which requires unobtrusively monitoring the users' environment and operating the equipment. Ambient Intelligence (AmI) technologies provide the necessary framework to address such requirements. The concept was coined in 2001 in the context of home-assistance technologies [27], bringing together contributions from sensor networks, pervasive computing and artificial intelligence to create smart environments that offer personalized services to improve the quality of life of their inhabitants [28]. AmI systems typically show the following characteristic features: context-awareness (they perceive the environment and act consequently); responsiveness (they react quickly); adaptiveness (they are attuned to the environment); transparency (they work unobtrusively); ubiquitousness (they can offer support anywhere at any time); and intelligence (they produce results similar to those provided by human intelligence).

To support the creation of the sensor network infrastructure, AmI can rely on the Internet of Things (IoT), a set of technologies for the interconnection of universally identifiable computing devices through the existing Internet. IoT has been recognized as a major driver of innovation in a considerable number of application areas [29], such as environmental monitoring, health care and, interestingly enough, efficient energy management in smart homes. 
Big data: The huge amount of data generated by sensors can be exploited to increase energy efficiency and to support user comfort management in the CaaS model. However, the large size of available sensor data poses several challenges to traditional data analysis approaches. Big data has emerged as a new set of technologies and a computing paradigm to manage vast amounts of data.

Energy service companies are not indifferent to this trend, and they are incorporated within their decision processes tools to analyze the big data generated by the sensors deployed in their energy grids and the smart meters installed at customers' homes [30]. CaaS requires powerful yet flexible data exploitation techniques to extract relevant knowledge from the data available from users' preferences, users' activities, equipment sensors and other influencing factors. This knowledge will not only drive the daily operation of the equipment, but also the network operations (e.g., prediction of future load peaks, maintenance investments) and the longer term commercial strategy (e.g., personalized tariffs and discounts) [31].

Cloud computing: Cloud computing is defined as a computing model and platform for "enabling ubiquitous, convenient, on-demand network access to a shared pool of configurable computing resources (e.g., networks, servers, storage, applications, and services) that can be rapidly provisioned and released with minimal management effort or service provider interaction" [32]. Therefore, it allows developing and consuming computing services without needing to be aware of the underlying architecture [33], offering the following advantages [34]: scalability, by dynamically assigning resources in real time; flexibility in the pricing model, since the cloud customer is charged for the resources that have been actually used; low administration efforts and responsibilities, which are transferred to the cloud providers; and mobility increment, because the cloud is accessible from any device as long as it can connect to the Internet.

Our vision of the realization of CaaS makes extensive use of the capabilities offered by cloud computing platforms; for instance, to minimize the cost associated with the maintenance and the upgrade of the computational infrastructure and to scale to respond to variable computational loads. However, cloud computing has important challenges ahead regarding data security and privacy, since users may not know which information has been collected from them, where it is stored and to whom it belongs. From a more technical point of view, due to the inherent distribution of resources, latency and connectivity issues can also be a problem for some users [35]. Last but not least, the cloud computing infrastructure itself has an impact on energy efficiency. To reduce the global cost of energy, it is necessary to reduce the consumption and the carbon footprint of the data centers that materialize the cloud. Hence, many companies have moved their infrastructures to Northern countries, where they can cool the equipment easily and cheaply, and are adopting the latest advances in low-power computing devices.

Predictive computing: Powered by the widespread availability of sensors, the computational capabilities of cloud computing and big data technologies, predictive computing is a new applied research area aimed at the development of smart services that gather and interpret data from user preferences, past and present activities and their environment to offer additional information, support, etc., even before they realize (or even imagine) these needs. Predictive systems are expected to be ubiquitous, with a notable presence in cars, homes, offices and mobile phones. We can consider smart thermostats and MPC control solutions as predictive computing enablers of the CaaS paradigm.

Nevertheless, predictive computing is not exempt of issues. Predictive systems need large amounts of data, including personal sensitive data. Moreover, even though available datasets may not include sensitive data, they can be revealed as a result of data combination and analysis. In the energy domain, it has been proven that it is not difficult to infer the behavioral patterns of the inhabitants of a house from their energy consumption data [36]. As discussed in Section 4, this can raise concerns for users. It is not clear how much users are willing to share, and in any case, it is compulsory to sort out several privacy and security problems, according to the law and ethical principles. 


\subsection{Architecture Proposal}

The enabling technologies can interoperate in different ways to materialize the CaaS vision. In Figure 1, we propose a prospective architecture of a CaaS system serving a set of domestic buildings. Our proposal is based on the combination of two components: a predictive control module, which uses MPC for long-term energy optimization, and a reactive control module, which uses local controllers for short-term adjustment of the operation.

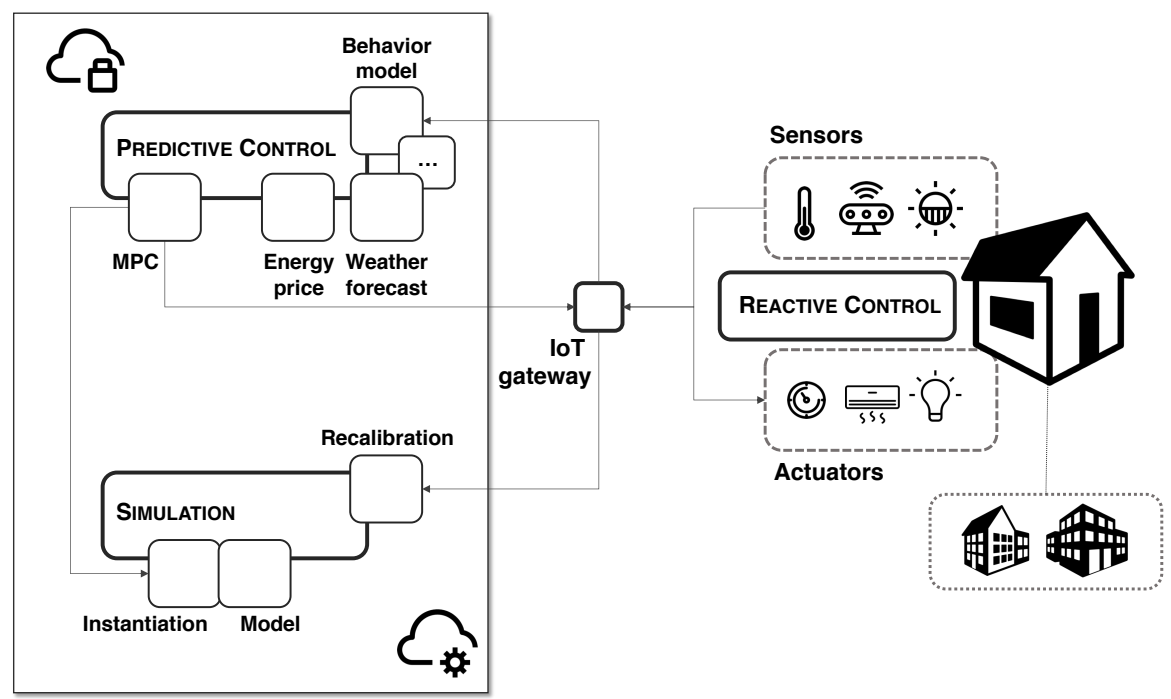

Figure 1. General architecture of a Comfort as a Service (CaaS) system.

Predictive control uses forecasted data to predict the building status and to create an operation plan consequently that minimizes energy consumption and cost while satisfying the comfort requirements defined in the SLA. To do so, the MPC components gather inhabitants' expected behavior, weather forecasts, energy prices and other relevant factors and simulate different operation plans, which are assessed according to consumption and comfort criteria. The underlying simulation model, instantiated for the specific building under consideration, is continuously recalibrated with building live data to minimize the simulation error. Analogously, the behavior model is continuously adapting to the users' habits and activities.

The plan selected by the predictive control module is eventually sent and applied in the building. Communication between the building and the module is performed through an IoT gateway, which allows receiving sensor data and sending control instructions. This communication channel must be secured to avoid unauthorized access and data leaks.

Predictive control software runs on the cloud, which facilitates dynamic allocation of computational resources, reduces maintenance costs and increases the availability of the system. The component can be as well encapsulated in a container (e.g., Docker or Kubernetes [37]), in such a way that it is possible to run one container per building or to have a parameterizable container per building type that is instantiated and executed on demand. In both cases, the execution can be parallelized at the intra-level (e.g., the simulation model of a building runs in parallel) and at the inter-level (e.g., simulations and predictions for multiple buildings are generated in parallel).

The reactive control module is used to adjust the operation calculated by the predictive control to specific building configurations and to unanticipated environmental conditions. Specifically, reactive control is activated when the comfort requirements are not achieved with the nominal setpoints, which happens when the real building conditions do not correspond to the estimations used by the predictive control module. Reactive control can be implemented with usual control 
technologies (e.g., PIDs and fuzzy controllers) or can incorporate more complex data analysis algorithms (e.g., intelligent thermostats).

All data generated by the system can be stored for further analysis and decision-making support. For example, it would be possible to identify frequent successful or failing plans. Given the large volume of data, storage and exploitation are implemented by using big data technologies. Big databases and machine learning algorithms can also run on the cloud, either on the same server instance of the control system or on dedicated servers; e.g., GPU-enabled servers to speed up massive computation.

In the last few years, there have been some research works proposing similar architectures, although not explicitly addressing the CaaS paradigm and mostly addressing non-residential buildings. As mentioned in the Introduction, the Energy IN TIME project is one of them [38]: IoT and big data for data collection and processing, cloud computing for parallel simulation execution and predictive computing for alternative scenario assessment are key to develop the new-generation building energy management systems. Similar ideas had been already explored by Marinakis et al. [39] and Rocha et al. [40], who defined a general architectures and implementations of intelligent building management systems. Previously, the RESILIENTproject set the foundations for applying these technologies at the district level in smart grids [41]. It is also interesting to mention the work by Cano et al. [42], who studied how the data generated by smart energy systems can be exploited for strategic decision-making.

\section{Economical and Social Aspects}

This section describes the SWOT analysis around CaaS, including a chart (Table 1) summarizing its main features. SWOT analysis is a strategic planning technique used to help identify the strengths, weaknesses, opportunities and threats related to business competition or project planning [43]. In particular, it aims to identify the key internal (strengths and weaknesses) and external factors (opportunities and threats) that affect the development of the project. While SWOT analysis is not exempt of its critics [44], it is a simple and widely-used tool to describe the current state of an initiative and to plan its future lines of action by providing insights into the barriers.

Table 1. SWOT chart for CaaS. SLA, Service-Level Agreement.

\begin{tabular}{ll}
\hline Strengths & Weaknesses \\
\hline + Better adaptation to demand & \\
+ Reduction of costs & - Surrender of energy control \\
+ Easiness of use & - Ethical aspects of SLAs \\
+ Quick response to failure & - Service neutrality is not enforced \\
+ Business scalability & \\
\hline Opportunities & Threats \\
\hline + Optimize equipment operation & \\
+ Increase energy efficiency & - Privacy \\
+ Integrated retrofitting and maintenance & - Security \\
+ Customer-adapter tariffs & \\
\hline
\end{tabular}

\subsection{Strengths and Opportunities}

CaaS offers interesting advantages for the service providers and the customers compared to the traditional user-operated comfort control. Users can benefit from a fixed monthly bill for the energy consumed by their HVAC and lighting equipment. As explained in Section 2, even when the climate conditions are very adverse, users are guaranteed a comfortable environment. In addition, users do not need to manage the installed equipment or understand its operation, as it will be controlled remotely by the service provider, who has a deep knowledge on how to operate efficiently for maximum performance. Furthermore, the provider can exploit the vast amount of data that it can collect about the customers and the influencing factors to improve energy management and increase efficiency. 
In particular, CaaS allows companies to know in advance the expected energy load and, consequently, to anticipate potential peaks and other problems. This is possible because the inherent uncertainty that users' behavior introduces in the system is notably reduced by limiting their control capabilities. Besides, if the CaaS provider can select among different energy sources, it will better schedule which one will be used depending on demand, production and prices. This also opens opportunities for promoting the use of green energies, which is appreciated by customers and may be publicly subsidized. Another advantage is that the subscription service produces a regular revenue to the company. It is as well possible for the provider to offer tariffs adapted to long-term weather predictions. For example, if meteorological data suggest a particularly warm winter, special seasonal discounts can be offered.

To operate successfully, CaaS requires the installation of specific devices inside users' homes to allow remote connectivity and to enable monitoring, control and automation capabilities. As shown in Figure 1, these devices include different sensors and actuators. In the worst case, it might be necessary to change or adapt the HVAC equipment. Studies show that users can support extra payments for energy-saving measures [45]. Nevertheless, depending on how much they consider as an acceptable fee, CaaS may not be viable under certain initial scenarios; e.g., those involving old buildings and equipment. This is in fact a trade-off that retrofitting projects also face.

In this regard, users can buy the additional equipment in advance or rent it. Since devices are remotely operated, CaaS makes it possible to update the control and monitoring software transparently, which improves the users' experience. This capability can be extended to support additional retrofitting actions, such as equipment maintenance and substitution during its whole life-cycle. The provider can recommend to customers different actions to improve the performance of the equipment and to replace the devices, with a view toward reducing energy consumption. In addition, automatic fault prevention and detection mechanisms can be implemented. Again, this reduction has evident benefits for both the user and the provider.

\subsection{Weaknesses and Threats}

As with any service provision, an SLA needs to be put in place between the service provider and the clients, in order to agree on the particular aspects of the service: quality, availability, responsibilities, etc. While electricity is a public utility (and hence bound to the common carrier regulation), comfort is not. Because of that and until a regulation is eventually put in place in that regard, CaaS might be subjected to different SLAs, with service providers being able to segment (or discriminate, in the worst case) their users for different reasons. One of those would be the payment of a premium fee, but more controversial ones could be related to different aspects of users' profiles (e.g., postal code), regardless of whether they are manually or automatically identified [46].

Another challenge of CaaS comes from the need to collect data acquired from the physical spaces of the users. First, sensible data collection must be compliant with well-accepted ethical and legal provisions. In this sense, the recent European General Data Protection Regulation (GDPR) established a legal framework to harmonize private data collection, storage and distribution in Europe [47]. Second, data leakage must be prevented by implementing appropriate technical means, since disclosure of personal and behavioral information about users could be exploited by malicious third parties in very different ways; e.g., for spamming purposes, or to commit a robbery when the user is not at home. The GDPR defines the Privacy Impact Assess (PIA) as the main tool to identify, describe and put safeguards on the processing of sensible information [48].

Finally, giving the control of the energy appliances to a third-party is not exempt of ethical issues. First and foremost, there is not a guarantee that the control is to be done in the best interest of the user beyond the SLA. In fact, one of the incentives of the CaaS model for the service provider is its ability to shape the comfort in the best way to suit its organization. While they will mostly be acceptable for users (and agreed upon by them), it is clear that on some occasions, the interest of the service provider will not be fully aligned with the user's preferred operation. From a more philosophical point of view, 
we can neither ignore the expected reluctance of potential customers to surrender control at home, as one of the innermost frontiers of personal freedom. For some people, the knowledge that their places are monitored, and they have yielded control of their equipment will certainly be scary and probably unacceptable.

\section{CaaS in a Real Setup}

Given the ambition of the CaaS approach, validating a wide-use system would require a long-term experimentation over a substantial number of use cases. We have however developed, in the context of the Energy IN TIME project, a small experiment to quantify the performance of an MPC-based system implementing the CaaS concept. By relying on a simulation model of a real hotel, we compared the energy consumption of the building either allowing or disallowing customers' heating control. The hotel is not strictly a residential building, but it resembles well their dynamics and, at the same time, facilitates the experimentation at a scale bigger than simpler model houses. In this section, we present some results using a simulation model of the Levi Panorama hotel in Finland. As we will see below, we can achieve energy savings by restricting customers' control without significant comfort decline. This opens several opportunities for CaaS deployments, which can make a profit from the saved energy margins.

The Levi Panorama hotel is located in Levi, a ski resort in Kittilä, a region in northern Finland located north of the Arctic Circle within the Lapland region. Kittilä has a subarctic climate, with strong seasonal shifts, as well as polar night and midnight sun. Levi Panorama activities are concentrated during the winter period, having an occupation level higher than $90 \%$ in the ski season. For the experiment, we created a simulation model of the accommodation areas in Floors 2 to 6, including common spaces and rooms, with the IESVE software (https:/ / www.iesve.com/VE2018). This section of the building is served by one Air Handling Unit (AHU) and one hydronic underfloor heating sub-system, for which the simulation model can reproduce different configurations; there is one temperature supply setpoint for each. Comfort is measured by means of 20 indoor air temperature sensors distributed over the rooms and the corridors of this area. For privacy reasons, the exact location of each sensor was not disclosed.

In the project, we developed a simulation-based algorithm to plan the best operation schedule for the next day considering the occupancy prediction and the weather forecast. This operational plan aims at optimizing the previous manual operation, which is essentially focused on always delivering enough heating power to allow customers to freely configure room thermostats at their will. With the new operation, clients cannot change their room temperature under the promise of guaranteed comfort. The details on how the plan is generated and applied in the building are out of the scope of this paper. What we want to show here is to what extent energy consumption can be reduced while guaranteeing users' comfort with an automated system, with a view on CaaS systems.

To answer this question, we selected three days in 2017 respectively corresponding to a prototypical average (standard: 27 February 2017), cold (harsh: 11 February 2017) and warm day (intermediate: 6 February 2017) of the winter season in Levi. For each day, we simulated the building behavior after:

- The normal real operation allowing clients' air conditioning adjustment (i.e., the base plan). The building energy demand was reconstructed from historical sensor data.

- The optimized operation not considering clients' air conditioning adjustment (i.e., the optimized plan). This plan was calculated by our MPC algorithm, which estimates the demand only from the forecasted external temperature and the predicted occupancy.

Afterwards, we analyzed the indoor air temperature values to estimate the expected comfort decline and the heating meter values to assess the potential energy savings.

Figure 2 shows a comparison of the normal operation versus a simplistic, but optimized plan for the intermediate winter day (6 February 2017). We can see that the base plan setpoint values are 
almost constant and high, whereas the optimized plan reduces the setpoint values in the middle of the day when the occupancy of the hotel is lower. The average indoor air temperature for each plan is shown in Figure 3, in which we can see that the optimized plan yields values around $21^{\circ} \mathrm{C}$, slightly slower than the base plan, but mostly within the comfort interval $[21,22]^{\circ} \mathrm{C}$. Note that the average outdoors air temperature this day was around $-12{ }^{\circ} \mathrm{C}$.

Most energy savings are achieved in the middle of the day, as illustrated in Figure 4; particularly when the supply temperature is lower and the outdoors air temperature is higher. It can be seen that we allowed a small discomfort (less than a quarter of a Celsius degree) by the end of the day, which resulted in a reduction of energy consumption. This is the kind of situation previously mentioned in Section 4.2 in which the company providing CaaS and the user may have opposite interests and must be regulated by the SLA.

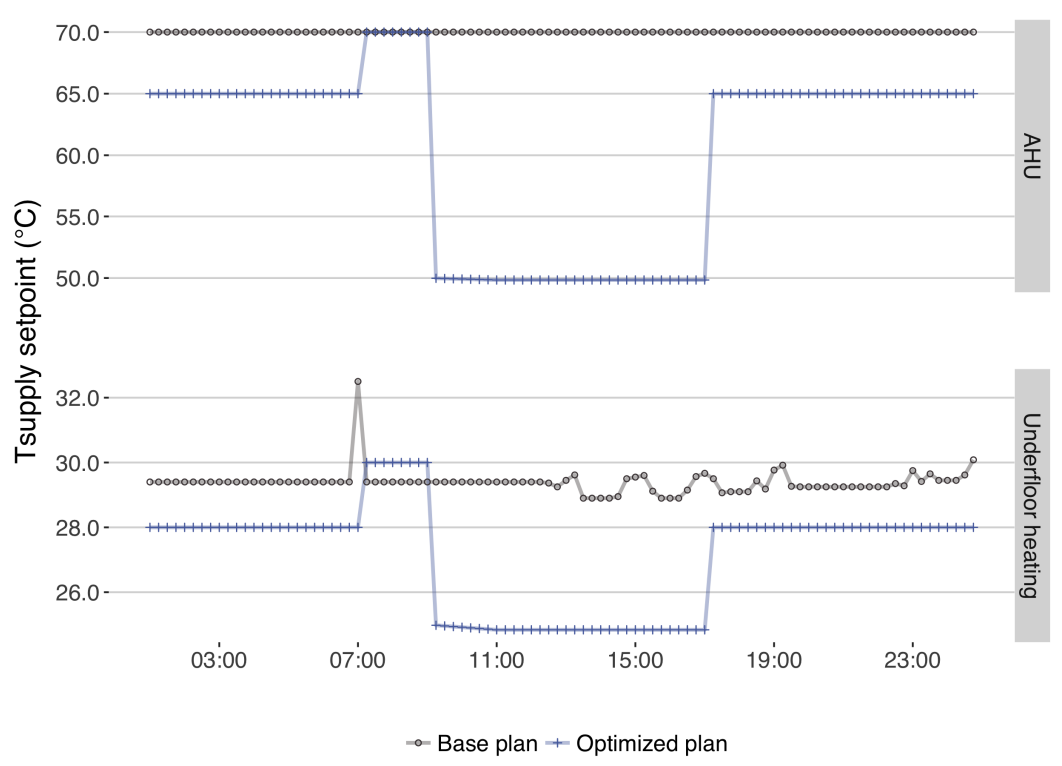

Figure 2. Temperature supply setpoint values of the base and the optimized operational plans simulated in the intermediate day (6 February 2017).

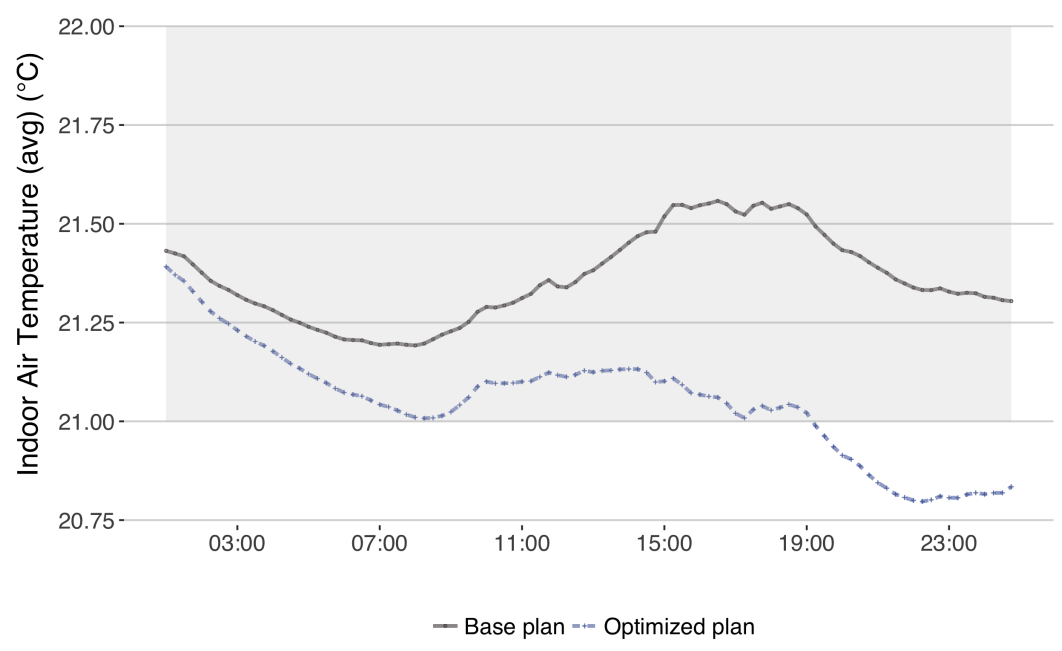

Figure 3. Indoor temperature values (average) of the base and the optimized operational plans obtained after simulation in the intermediate day (6 February 2017) (the comfort range [21, 22] is highlighted). 


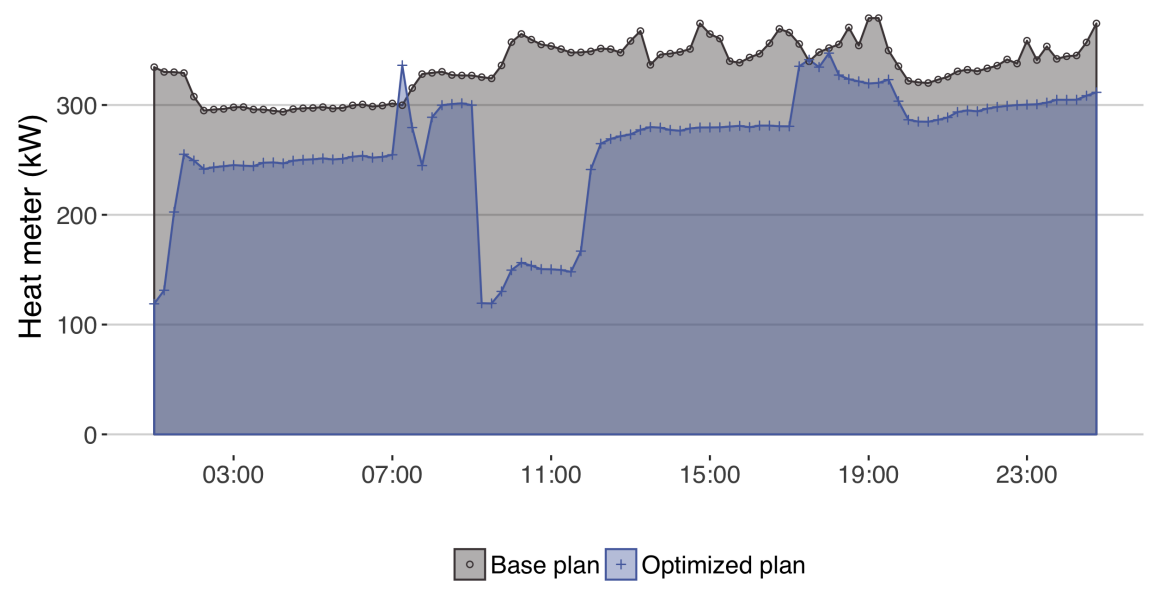

Figure 4. Power consumption of the base and the optimized operational plans obtained after simulation in the intermediate day (6 February 2017).

As expected, savings in the standard day and, particularly, in the harsh day are more modest; see Table 2. The lower the external temperature, the more difficult it is to reduce the setpoint values without significant comfort decline, even during the less busy hours. The HVAC system of the hotel is already working at maximum capacity just to barely achieve comfort, and therefore, further reductions must be very selective. Moreover, if the building temperature falls down too much, it is not possible to raise it up later to reach the comfort interval. Besides, despite the lower occupancy in the middle of the day, there are still people in the building for whom a minimum comfort must be guaranteed.

Considering that winter in Levi is a quite extreme case, we can expect that milder climates with more 'intermediate' days will offer more chances for optimized control and, therefore, more business opportunities for CaaS. As a matter of fact, in the Energy IN TIME project, we achieved savings of around $30 \%$ in the remaining demo sites, including an office building in Bucharest (Romania), a commercial building in Helsinki (Finland) and the Faro airport (Portugal). These figures are in line with similar studies in the literature, which have shown that MPC-enabled systems can achieve energy savings up to $35 \%$ [49].

Table 2. Energy savings of the base and the optimized operational plans obtained after simulation of the three reference days: (a) standard day (27 February 2017); (b) harsh day (11 February 2017); (c) intermediate day (6 February 2017).

\begin{tabular}{lccc}
\hline & Standard & Harsh & Intermediate \\
\hline Outdoors temperature $\left(\right.$ average $\left.{ }^{\circ} \mathrm{C}\right)$ & -11.6 & -20.3 & -8.0 \\
Base plan $(\mathrm{kWh})$ & 8671.33 & $10,883.27$ & 7932.28 \\
Optimized plan $(\mathrm{kWh})$ & 7436.48 & 9673.75 & 6253.14 \\
\hline Savings $(\%)$ & 14.24 & 11.11 & 21.17 \\
\hline
\end{tabular}

\section{Conclusions}

This paper has presented the concept of comfort as a service, a new economic paradigm for providing residential users with comfort by means of automated control of the HVAC and lighting equipment according to the environmental conditions and the users' preferences. CaaS emerges as a disruptive model with respect to the traditional practice of paying for consumed energy, offering advantages to the consumers and to the energy service companies.

CaaS also offers several incentives to reduce energy consumption to both parties. This is a very relevant implication, because a great deal of the energy consumed in residential buildings is due to inefficient operation of the HVAC systems. 
The implementation of the CaaS model is based on several cutting-edge information and communication technologies. Not exhaustively, we have described in this work ambient intelligence, cloud computing, big data and predictive computing. These technologies provide a suitable and flexible computational infrastructure to support the processes of data collection, analysis and exploitation. However, there are some issues that still need to be investigated. Among them, guaranteeing data privacy and security is one of the most important due to its social and technological implications. Studying the social acceptance of CaaS also remains as an interesting direction for future work.

Initial experiments in a simulated environment have shown that there is considerable room for energy saving if users capabilities to manage HVAC systems are limited, which opens several opportunities for CaaS business.

Author Contributions: All authors contributed to the conceptualization of the research work and to the writing of the original draft. J.G.-R. and M.M.-S. led the review and editing process.

Funding: This research was partially funded by EU-FP7 (Energy IN TIME project, Grant Agreement No. 608981), the Spanish Government (TIN2015-30939 project) and Universidad de Granada (Young Researchers Fellowship, No. P9-2014-ING).

Conflicts of Interest: The authors declare no conflict of interest.

\section{References}

1. Liang, H.H.; Chen, C.P.; Hwang, R.L.; Shih, W.M.; Lo, S.C.; Liao, H.Y. Satisfaction of occupants toward indoor environment quality of certified green office buildings in Taiwan. Build. Environ. 2014, 72, $232-242$. [CrossRef]

2. Nguyen, T.A.; Aiello, M. Energy intelligent buildings based on user activity: A survey. Energy Build. 2013, 56, 244-257. [CrossRef]

3. Zagreus, L.; Huizenga, C.; Arens, E.; Lehrer, D. Listening to the occupants: A Web-based indoor environmental quality survey. Indoor Air 2004, 14, 65-74. [CrossRef] [PubMed]

4. Kerber, T. Residential Energy Savings through Data Analytics; Technical Report; Parks Associated: Dallas, TX, USA, 2013.

5. Afram, A.; Janabi-Sharifi, F. Theory and applications of HVAC control systems-A review of model predictive control (MPC). Build. Environ. 2014, 72, 343-355. [CrossRef]

6. prEN 16798-2:2015-Guideline for Using Indoor Environmental Input Parameters for the Design and Assessment of Energy Performance of Buildings; Comité Europeén de Normalisation (CEN): Brussels, Belgium, 2015.

7. ANSI/ASHRAE Standard 55-Thermal Environmental Conditions for Human Occupancy; American National Standards Institute: Washington, DC, USA, 2017.

8. Rupp, R.F.; Vásquez, N.G.; Lamberts, R. A review of human thermal comfort in the built environment. Energy Build. 2015, 105, 178-205. [CrossRef]

9. Fanger, P. Thermal Comfort: Analysis and Applications in Environmental Engineering; McGraw-Hill: New York, NY, USA, 1970.

10. Schaudienst, F.; Vogdt, F.U. Fanger's model of thermal comfort: a model suitable just for men? Energy Procedia 2017, 132, 129-134. [CrossRef]

11. Freire, R.Z.; Oliveira, G.H.; Mendes, N. Predictive controllers for thermal comfort optimization and energy savings. Energy Build. 2008, 40, 1353-1365. [CrossRef]

12. Lim, J.H.; Cho, S.H.; Yun, G.Y. Development of the adaptive PMV model for improving prediction performances. Energy Build. 2015, 98, 100-105.

13. Astrom, K.J.; HÄgglund, T. Advanced PID Control; International Society of Automation: Research Triangle Park, NC, USA, 2006.

14. Molina-Solana, M.; Ros, M.; Delgado, M. Unifying Fuzzy controller for Indoor Environment Quality. In Proceedings of the 2013 Joint IFSA World Congress and NAFIPS Annual Meeting (IFSA/NAFIPS), Edmonton, AB, Canada, 24-28 June 2013; pp. 1080-1085. [CrossRef]

15. Afroz, Z.; Sha, G.M.; Urmee, T.; Higgins, G. Modeling techniques used in building HVAC control systems: A review. Renew. Sustain. Energy Rev. 2017, 83, 64-84. [CrossRef] 
16. Petersen, S.; Bundgaard, K.W. The effect of weather forecast uncertainty on a predictive control concept for building systems operation. Appl. Energy 2014, 116, 311-321. [CrossRef]

17. Sheth, J.N.; Sethia, N.K.; Srinivas, S. Mindful consumption: a customer-centric approach to sustainability. J. Acad. Market. Sci. 2011, 39, 21-39. [CrossRef]

18. Allcott, H.; Mullainathan, S. Behavior and Energy Policy. Science 2010, 327, 1204-1205. [CrossRef] [PubMed]

19. Moreno, M.V.; Zamora, M.A.; Skarmeta, A.F. User-centric smart buildings for energy sustainable smart cities. Trans. Emerg. Telecommun. Technol. 2014, 25, 41-55. [CrossRef]

20. Abrahamse, W.; Steg, L.; Vlek, C.; Rothengatter, T. The effect of tailored information, goal setting, and tailored feedback on household energy use, energy-related behaviors, and behavioral antecedents. J. Environ. Psychol. 2007, 27, 265-276. [CrossRef]

21. Abrahamse, W.; Steg, L.; Vlek, C.; Rothengatter, T. A review of intervention studies aimed at household energy conservation. J. Environ. Psychol. 2005, 25, 273-291. [CrossRef]

22. Darby, S. Smart metering: What potential for householder engagement? Build. Res. Inf. 2010, 38, 442-457. [CrossRef]

23. Rollins, S.; Banerjee, N. Using rule mining to understand appliance energy consumption patterns. In Proceedings of the 2014 IEEE International Conference on Pervasive Computing and Communications (PerCom), Budapest, Hungary, 24-28 March 2014; pp. 29-37. [CrossRef]

24. Yu, Z.; Fung, B.C.; Haghighat, F.; Yoshino, H.; Morofsky, E. A systematic procedure to study the influence of occupant behavior on building energy consumption. Energy Build. 2011, 43, 1409-1417. [CrossRef]

25. Al-Mumin, A.; Khattab, O.; Sridhar, G. Occupants' behavior and activity patterns influencing the energy consumption in the Kuwaiti residences. Energy Build. 2003, 35, 549-559. [CrossRef]

26. Zhao, J.; Lasternas, B.; Lam, K.; Yun, R.; Loftness, V. Occupant behavior and schedule modeling for building energy simulation through office appliance power consumption data mining. Energy Build. 2014, 82, 341-355. [CrossRef]

27. Ducatel, K.; Bogdanowicz, M.; Scapolo, F.; Leijten, J.; Burgelman, J.C. Scenarios for Ambient Intelligence in 2010; Technical Report; IST Advisory Group: University Park, PA, USA, 2001.

28. Cook, D.J.; Augusto, J.C.; Jakkula, V.R. Ambient intelligence: Technologies, applications, and opportunities. Pervasive Mob. Comput. 2009, 5, 277-298. [CrossRef]

29. Rifkin, J. The Zero Marginal Cost Society: The Internet of Things, the Collaborative Commons, and the Eclipse of Capitalism; St. Martin's Press: New York, NY, USA, 2014.

30. IBM. Managing Big Data for Smart Grids and Smart Meters; White Paper; IBM Software: New York, NY, USA, 2012.

31. Molina-Solana, M.; Ros, M.; Ruiz, M.D.; Gómez-Romero, J.; Martin-Bautista, M. Data Science for Building Energy Management: A review. Renew. Sustain. Energy Rev. 2017, 70, 598-609. [CrossRef]

32. Mell, P.; Grance, T. The NIST Definition of Cloud Computing. Recomm. Natl. Inst. Stand. Technol. 2011. [CrossRef]

33. Buyya, R.; Yeo, C.S.; Venugopal, S.; Broberg, J.; Brandic, I. Cloud computing and emerging IT platforms: Vision, hype, and reality for delivering computing as the 5th utility. Future Gener. Comput. Syst. 2009, 25, 599-616. [CrossRef]

34. Sadiku, M.N.; Musa, S.M.; Momoh, O.D. Cloud Computing: Opportunities and Challenges. IEEE Potentials 2014, 33, 34-36. [CrossRef]

35. Grobauer, B.; Walloschek, T.; Stocker, E. Understanding Cloud Computing Vulnerabilities. IEEE Secur. Priv. 2011, 9, 50-57. [CrossRef]

36. McDaniel, P.; McLaughlin, S. Security and privacy challenges in the smart grid. IEEE Secur. Priv. 2009, 7, 75-77. [CrossRef]

37. Bernstein, D. Containers and Cloud: From LXC to Docker to Kubernetes. IEEE Cloud Comput. 2014, 1, 81-84. [CrossRef]

38. Conserva, A.; de Melo, P.; Klebow, B.; Conaghan, C.; Vinot, B.; Gómez-Romero, J.; Ruiz, M.D.; Martin-Bautista, M.J.; Heino, J.; Voisin, A.; et al. Energy in Time Project: summary of final results. In Proceedings of the 12th Conference on Sustainable Development of Energy, Water and Environment Systems (SDEWES 2017), Dubrovnik, Croatia, 4-8 October 2017.

39. Marinakis, V.; Doukas, H.; Karakosta, C.; Psarras, J. An integrated system for buildings' energy-efficient automation: Application in the tertiary sector. Appl. Energy 2013, 6-14. [CrossRef] 
40. Rocha, P.; Siddiqui, A.; Stadler, M. Improving energy efficiency via smart building energy management systems: A comparison with policy measures. Energy Build. 2015, 88, 203-213. [CrossRef]

41. Howell, S.; Rezgui, Y.; Hippolyte, J.L.; Jayan, B.; Li, H. Towards the next generation of smart grids: Semantic and holonic multi-agent management of distributed energy resources. Renew. Sustain. Energy Rev. 2017, 77, 193-214. [CrossRef]

42. Cano, E.L.; Groissböck, M.; Moguerza, J.M.; Stadler, M. A strategic optimization model for energy systems planning. Energy Build. 2014, 81, 416-423. [CrossRef]

43. Helms, M.; Nixon, J. Exploring SWOT analysis-Where are we now?: A review of academic research from the last decade. J. Strategy Manag. 2010, 3, 215-251. [CrossRef]

44. Hill, T.; Westbrook, R. SWOT Analysis: It's Time for a Product Recall. Long Range Plan. 1997, 30, 46-52. [CrossRef]

45. Banfi, S.; Farsi, M.; Filippini, M.; Jakob, M. Willingness to pay for energy-saving measures in residential buildings. Energy Econ. 2008, 30, 503-516. [CrossRef]

46. Schermer, B.W. The limits of privacy in profiling and data mining. Comput. Law Secur. Rev. 2011, $27,45-52$. [CrossRef]

47. Tikkinen-Piri, C.; Rohunen, A.; Markkula, J. EU General Data Protection Regulation: Changes and implications for personal data collecting companies. Comput. Law Secur. Rev. 2018, 34, 134-153. [CrossRef]

48. Wright, D.; De Hert, P. Introduction to Privacy Impact Assessment. In Privacy Impact Assessment; Springer: Berlin, Germany, 2012; pp. 3-32.

49. Ghahramani, A.; Zhang, K.; Dutta, K.; Yang, Z.; Becerik-Gerber, B. Energy savings from temperature setpoints and deadband: Quantifying the influence of building and system properties on savings. Appl. Energy 2016, 165, 930-942. [CrossRef]

(C) 2018 by the authors. Licensee MDPI, Basel, Switzerland. This article is an open access article distributed under the terms and conditions of the Creative Commons Attribution (CC BY) license (http://creativecommons.org/licenses/by/4.0/). 